\title{
ANALISIS CUSTOMER RELATIONSHIP MANAGEMENT TERHADAP LOYALITAS MELALUI KEPUASAN PELANGGAN PT PELABUHAN INDONESIA IV (PERSERO) MAKASSAR
}

\author{
Muh. Fuad Randy \\ Program Studi Manajemen, Sekolah Tinggi Ilmu Ekonomi YPUP \\ Email: fuadypup@gmail.com
}

\begin{abstract}
Business competition is getting tighter, so many companies must be able to know and fulfill the wants or needs of their customers precisely. The level of competition is so tight that many companies no longer focus their marketing activities solely on finding new buyers / customers, but on how to maintain and increase customer loyalty. The strategy that is able to bridge between customers and companies, especially in terms of satisfaction and loyalty, is to apply a concept called Customer Relationship Management (CRM). This study aims to determine the effect of CRM both on satisfaction and loyalty partially and to know the indirect effect of CRM on loyalty through customer satisfaction as an intervening variable by drawing a sample of 60 people or customers. Based on the results of testing the coefficient of determination, it is known that the effect of CRM on customer satisfaction is $20.5 \%$ and the remaining $79.5 \%$ is influenced by other variables which are not addressed in this study. While the test results of the coefficient of determination in the second regression equation show that the CRM variable and customer satisfaction affect the level of customer loyalty by $44.8 \%$ and the remaining $55.2 \%$ is influenced by other variables which are not raised in this study. However, from the results of testing the intervening variable that customer satisfaction is not an intervening variable between CRM and customer loyalty.

Keyword : CRM, Loyality, Customer Satisfaction
\end{abstract}

\begin{abstract}
Abstrak
Persaingan bisnis semakin ketat mengakibatkan banyak perusahaan harus mampu mengetahui dan memenuhi keinginan atau kebutuhan para pelanggan dengan tepat. Tingkat persaingan yang begitu ketat mengakibatkan banyak perusahaan tidak lagi memfokuskan aktifitas pemasaran semata-semata pada pencarian pembeli/pelanggan baru, namun sudah pada bagaimana mempertahankan serta meningkatkan kesetiaan pelanggan. strategi yang mampu menjembatani antara pelanggan dan perusahaan terutama dalam hal kepuasan dan loyalitas adalah dengan menerapkan konsep yang disebut dengan Customer Relationship Management (CRM). Penelitian ini bertujuan untuk mengetahui pengaruhnya CRM baik terhadap kepuasan maupun loyalitas secara parsial serta mengetahui pengaruhnya CRM secara tidak langsung terhadap loyalitas melalui kepuasan pelanggan sebagai variable intervening dengan penarikan sampel sebanyak 60 orang atau pelanggan. Berdasarkan hasil pengujian koefisien determinasi diketahui adanya pengaruh CRM terhadap kepuasan pelanggan sebesar 20,5\% dan 79,5\% sisanya di pengaruhi variable lain yang tidak diangkat dalam penelitian ini. Sedangkan hasli pengujian koefisien determinasi pada persamaan regresi ke dua bahwa variable CRM dan kepuasan pelanggan mempengaruhi tingkat loyalitas pelanggan sebesar $44,8 \%$ dan sisanya $55,2 \%$ dipengaruhi oleh variable lain yang tidak diangkat dalam penelitian ini. Namun dari hasil pengujian variable intervening bahwa kepuasan pelanggan tidak menjadi variable intervening diantara CRM dan loyalitas pelanggan.
\end{abstract}

Kata Kunci: CRM, Loyalitas, Kepuasan Pelanggan

\section{Pendahuluan}

Banyak perusahaan akhir-akhir ini berlomba-lomba untuk memberikan benefit tertinggi terhadap pelanggan setianya. Mengingat bahwa delapan puluh persen ( $80 \%)$ pendapatan yang diperoleh perusahaan merupakan kontribusi (pemasukan) dari dua puluh persen (20\%) jumlah pelanggan yang ada (Chan, 2003). pentingnya suatu strategi pemasaran yang mampu menumbuhkan ikatan (hubungan) antara pelanggan dan perusahaan guna menjalin komunikasi dan hubungan jangka panjang yang saling menguntungkan dengan pelanggan. 
Salah satu strategi yang mampu menjembatani antara pelanggan dan perusahaan adalah menerapkan suatu konsep yang disebut dengan Customer Relationship Management atau yang biasanya disingkat menjadi CRM, yang mengintegrasikan antara people, process, dan technology sehingga tercipta suatu komunikasi yang baik dengan pelanggan terutama guna menumbuhkan loyalitas pelanggan kepada perusahaan. Dalam kontek pasar yang sudah sangat tercerahkan terutama dalam penggunaan teknologi CRM sekarang sudah semakin meningkat penggunaannya dengan memadukan teknologi yang disebut sebagai e-CRM (Mashur et al, 2019) CRM sebagai salah satu fungsi dalam dimensi relationship marketing merupakan media untuk meningkatkan loyalitas pelanggan (Latief F, 2019). CRM merupakan proses keseluruhan dalam mengindentifikasi, menarik, mendiferensiasi, mempertahankan pelanggan dengan jalan mengintegrasi rantai pasokan perusahaan guna menciptakan nilai konsumen pada setiap langkah dalam peroses penciptaan nilai (Tjiptono, 2014). Kepuasan pelanggan menjadi factor utama dalam terciptanya suatu kesetiaan pelanggan atau kata lainya loyalitas, dengan merasa puas terhadap produk maupun jasa maka secara otomatis pelanggan akan kembali lagi untuk membeli dan menggunaka/merasakan produk atau jasa tersebut. Apabila perusahaan gagal dalam memuaskan pelanggannya nantinya akan berdampak beralihnya pelanggan atau pemasok lain baik untuk produksi sejenis maupun produk subsitusi.

Loyalitas pelanggan juga menjadi suatu point penting bagi perusahaan untuk membangun hubungan yang baik terhadap perusahaan.(Barnes, 2003) menyatakan loyalitas pelanggan adalah suatu hubungan emosional antara pembeli (pelanggan) dengan perusahaan, dan ini bisa dibuktikan dengan transaksi yang berulang - ulang. Sedangkan menurut (Sellyana Junaidi dan Basu Swastha, 2016) yaitu konsep yang menekankan terhadap pembelian atau transaksi yang berulang-ulang, maka dengan transaksi yang berulang tersebut menandakan adanya kepuasan pelanggan pada perusahaan PT Pelindo IV (Persero) . Itu diperjelas dari (Kotler, 2014) Perasaan senang atau kecewa yang muncul setelah membandingkan kinerja (hasil) produk yang dipikirkan terhadap kinerja (atau hasil) yang diharapkan.

PT Pelabuhan Indonesia IV (Persero) atau biasa disebut PT Pelindo IV (Persero) merupakan perusahan Badan Usaha Milik Negara (BUMN) yang bergerak pada bidang jasa kepelabuhanan. PT Pelindo IV (Persero) mempunyai suatu value dalam melayani pelanggan yang dikenal dengan sebutan INTANKU PELANGGAN yang dimana konsen kepada Integritas, Antusias, Kolaborasi, Kompeten, serta Fokus Pelanggan. Dengan mengedepankan Visi menjadi perusahaan yang bernilai dan berdaya Tarik tinggi melalui proses dan pelayanan unggul dengan orang-orang yang bahagia. Hal tersebut dapat dilihat bahwa PT Pelindo IV (Persero) sangat mengedepankan kepuasan pelanggan, ini terbukti dengan adanya beberapa fasilitas yang memadai seperti adanya ruang tunggu yang full $\mathrm{AC}$, adanya televison, toilet, dan bahkan disediakan ruang untuk menyusui serta ruang bermain anak-anak di beberapa cabang PT Pelindo IV (Persero).

Hubungan fungsi dari CRM terhadap kepuasan pelanggan serta loyalitas pelanggan inilah yang menjadikan CRM sebagai salah satu strategi yang sangat diperhatikan Perusahaan. Dengan diterapkannya strategi ini dapat membuat perusahaan menjadi penguasa pasar walaupun PT Pelindo IV (Persero) merupakan perusahaan BUMN yang bisa dikatakan sebagai perusahaan Monopoli khususnya pada bidang jasa kepelabuhanan, namun tidak menutup kemungkinan penelitian ini diharapkan memberikan ide dan inovasi dalam strategi CRM guna membangun intensitas pemakaian jasa dan loyalitas pelanggan terhadap jasa yang ditawarkan oleh PT Pelindo IV (Persero). Penelitian ini mengambil lokasi Cabang Makassar, dikarenakan PT Pelindo IV (persero) Cabang Makassar merupakan salah satu pelabuhan hub di wilayah timur Indonesia sehingga menarik peneliti untuk mengkaji lebih jauh terkait pengaruh CRM terhadap loyalitas melalui kepuasan pelanggan pada PT Pelindo IV (Persero) Cabang Makassar. 


\section{AkMen}

\section{Metode}

1. Jenis dan Sumber Data

Penelitian ini dilakukan dengan pendekatan kuantitatif, yang bertujuan untuk menganalisa hubungan sebab-akibat dengan cara mengamati akibat yang terjadi dan kemungkinan faktor (sebab) yang menimbulkan akibat tersebut serta menampilkan informasi yang diperoleh dalam bentuk numerik (Singarimbun dan Effendi, 2006). Sumber data dalam penelitian ini menggunakan pendekatan data sekunder (data pendukung yang diperoleh dari studi dokumentasi) dan primer (data yang diperoleh dari interview maupun jawaban dari daftar pertannyaan dalam bentuk kuesioner).

2. Metode Analisis Data

Populasi adalah wilayah generalisasi yang terdiri dari objek dan subjek yang mempunyai kualitas dan karakteristik tertentu yang diterapkan oleh penulis untuk dipelajari dan ditarik kesimpulannya (Sugiono, 2017). Adapun yang menjadi popuasi dalam penelitian ini adalah pengguna jasa PT Pelabuhan Indonesia IV (Persero) pada cabang Makassar yang dimana ditarik sampel sebesar 60 pengguna jasa yang telah menngunakan jasa kepelabuhanan Cabang Makassar minimal 2 tahun atau lebih. Analisis data merupakan proses pengolahan, penyajian, interpretasi dan analisis data yang diperoleh dari lapangan, dengan tujuan agar data yang disajikan mempunyai makna, sehingga pembaca dapat mengetahui hasil penelitian yang dilakukan (Martono, 2011). Dalam menentukan analisis data, diperlukan data yang akurat dan dapat dipercaya yang nantinya dapat dipergunakan dalam penelitian yang dilakukan oleh penulis. Analisis data merupakan proses penyederhanaan data kedalam bentuk yang lebih mudah dibaca, dipahami dan diinterpretasikan.

Analisis data yang dilakukan dengan bantuan dari program SPSS Versi 21 sebagi alat untuk meregresikan model yang telah dirumuskan. Teknik analisis data yang digunakan dalam penelitian ini adalah statistika deskriptif, yakni dengan tabulasi data dari responden untuk menentukan jumlah dan persentase responden. Pengujian statistik deskripsi untuk variable penelitian variabel Customer Relationship Management, Kepuasan dan Loyalitas Pelanggan pada PT Pelabuhan Indonesia IV (Persero) Cabang Makassar.

\section{Hasil}

\section{Uji Jalur (Path Analysis)}

Analisis jalur pada penelitian ini terdiri atas dua (2) regresi. analysis regresi pertama (I) bertujuan untuk mengetahui pengaruh langsung antara Customer Relationship Management (CRM) terhadap Kepuasan Pelanggan sedangkan analisis regresi kedua (II) bertujuan untuk mengetahui pengaruh tidak langsung antara Customer Relationship Management (CRM) terhadap Loyalitas Pelanggan melalui Kepuasan Pelanggan.

Hasil regresi pertama (I) untuk mengetahui pengaruh langsung antara Customer Relationship Management (CRM) terhadap Kepuasan Pelanggan dapat dilihat pada Tabel 1:

Tabel 1

Coefficientsa

\begin{tabular}{|c|c|c|c|c|c|}
\hline \multirow[b]{2}{*}{ Model } & \multicolumn{2}{|c|}{ Unstandardized Coefficients } & \multirow{3}{*}{$\begin{array}{c}\text { Standardized } \\
\text { Coefficients } \\
\text { Beta }\end{array}$} & \multirow[b]{2}{*}{$\mathrm{t}$} & \multirow[b]{2}{*}{ Sig. } \\
\hline & B & Std. Error & & & \\
\hline $1 \quad$ (Constant) & 7.453 & 2.671 & & 2.790 & .007 \\
\hline CRM (X) & .180 & .046 & .452 & 3.863 & .000 \\
\hline
\end{tabular}

Sumber: Pengolahan Data Primer menggunakan SPSS, 2020

Berdasarkan hasil regresi pertama (I) pada Tabel 1, diperoleh persamaan regresi pertama (I) sebagai berikut:

$$
\mathrm{Y}=7,453+0,180 \mathrm{X}+\mathrm{el}
$$


Persamaan regresi pertama (I) tersebut memiliki arti bahwa Customer Relationship Management (CRM) terhadap kepuasan pelanggan dengan nilai koefisien sebesar 0,180. Jika Customer Relationship Management (CRM) mengalami kenaikan sebesar 1 satuan maka Kepuasan Pelanggan akan mengalami kenaikan sebesar 0,180. Adapun nilai konstanta (a) sebesar 7,453 artinya jika Customer Relationship Management (CRM) memiliki nilai sebesar 0, maka kepuasan pelanggan bernilai konstan sebesar 7,453.

Kemudian hasil pengujian koefisien determinasi $\left(\mathrm{R}^{2}\right)$ pada persamaan regresi pertama (1) dapat dilihat pada Tabel 2.

Tabel 2

\begin{tabular}{|c|c|c|c|c|}
\hline \multicolumn{5}{|c|}{ Model Summary } \\
\hline Model & $\mathrm{R}$ & R Square & $\begin{array}{c}\text { Adjusted R } \\
\text { Square } \\
\end{array}$ & $\begin{array}{r}\text { Std. Error of the } \\
\text { Estimate }\end{array}$ \\
\hline 1 & $.452^{\mathrm{a}}$ & .205 & 191 & 1. 321 \\
\hline
\end{tabular}

Sumber: Pengolahan Data Primer menggunakan SPSS, 2020

Berdasarkan Tabel 2, diperoleh nilai R2 sebesar 0,205. Nilai tersebut dapat diinterprestasikan bahwa variable Customer Relationship Management (CRM) dapat menjelaskan variable Kepuasan Pelanggan sebesar 20,5\% dan sisanya 79,5\% dijelaskan oleh variable lain yang tidak dikaji pada penelitian ini. Selanjutnya dari hasil regresi diatas dapat di tentukan nilai el $=\sqrt{1-\mathrm{R} 2}=\sqrt{1-0,205}=0,795$. Selanjutnya hasil regresi II untuk mengetahui pengaruh tidak langsung antara Customer Relationship Management (CRM) terhadap Loyalitas melalui Kepuasan Pelanggan dapat dilihat pada Tabel 3:

Tabel 3

Coefficients $^{\mathrm{a}}$

\begin{tabular}{|c|c|c|c|c|c|c|}
\hline \multirow[b]{2}{*}{ Model } & & \multicolumn{2}{|c|}{ Unstandardized Coefficients } & \multirow{2}{*}{$\begin{array}{c}\text { Standardized } \\
\text { Coefficients } \\
\text { Beta }\end{array}$} & \multirow[b]{2}{*}{$\mathrm{t}$} & \multirow[b]{2}{*}{ Sig. } \\
\hline & & $\mathrm{B}$ & Std. Error & & & \\
\hline \multirow[t]{3}{*}{1} & (Constant) & 3.372 & 2.272 & & 1.484 & .143 \\
\hline & $\mathrm{CRM}(\mathrm{X})$ & .093 & .042 & .247 & 2.238 & .029 \\
\hline & Kepuasan (Z) & .495 & .105 & .521 & 4.721 & .000 \\
\hline
\end{tabular}

a. Dependent Variable: Loyalitas (Y)

Sumber: Pengolahan Data Primer menggunakan SPSS, 2020

Berdasarkan hasil regresi kedua (II) pada Tabel 4.17, diperoleh persamaan regresi II sebagai berikut:

$$
\mathrm{Y}=3,372+0,093 \mathrm{X}+0,495 \mathrm{Z}+\mathrm{el}
$$

Persamaan regresi II tersebut memiliki arti bahwa Customer Relationship Management dan Kepuasan Pelanggan berpengaruh positif terhadap Loyalitas Pelanggan dengan nilai koefisien masing-masing sebesar 0,093 dan 0,495. Jika Customer Relationship Management mengalami kenaikan sebesar 1 satuan maka Loyalitas Pelanggan akan mengalami kenaikan sebesar 0,093. Begitu juga jika Kepuasan Pelanggan mengalami kenaikan sebesar 1 satuan maka turut memberikan kontribusi sebesar 0,495 terhadap Loyalitas Pelanggan. Adapun nilai konstanta (a) sebesar 3,372 artinya jika Customer Relationship Management dan 
Kepuasan Pelanggan memiliki nilai sebesar 0, maka Kepuasan Pelanggan bernilai konstan sebesar 3,372.

Kemudian berdasarkan Tabel 3, diketahui nilai signifikansi Customer Relationship Management dan Kepuasan Pelanggan masing-masing sebesar 0,029 dan 0,000 pada $\alpha=10 \%$. Hal tersebut menunjukkan bahwa hipotesis II dan III diterima, dimana menyatakan bahwa Customer Relationship Management dan Kepuasan Pelanggan secara parsial berpengaruh positif dan signifikan terhadap Loyalitas Pelanggan di PT Pelabuhan Indonesia IV (Persero) Cabang Makassar.

Kemudian hasil pengujian koefisien determinasi (R2) pada persamaan regresi II dapat dilihat pada Tabel 4:

Tabel 4

Model Summary

\begin{tabular}{|cc|c|c|cr|}
\hline Model & R & R Square & \multicolumn{2}{c|}{$\begin{array}{c}\text { Adjusted R } \\
\text { Square }\end{array}$} & \multicolumn{2}{c|}{$\begin{array}{c}\text { Std. Error of the } \\
\text { Estimate }\end{array}$} \\
\hline 1 & $.670 \mathrm{a}$ & .448 & .429 & & 1.055 \\
\hline
\end{tabular}

a. Predictors: (Constant), Kepuasan (Z), CRM (X)

Sumber: Pengolahan Data Primer menggunakan SPSS, 2020

Berdasarkan Tabel 4, diperoleh nilai R2 sebesar 0,448. Nilai tersebut dapat diinterprestasikan bahwa variable Customer Relationship Management (CRM) dan Kepuasan Pelanggan dapat menjelaskan variable Loyalitas Pelanggan sebesar 44,8\% dan sisanya 55,2\% dijelaskan oleh variable lain yang tidak dikaji pada penelitian ini. Selanjutnya dari hasil regresi diatas dapat di tentukan nilai e2 $=\sqrt{1-\mathrm{R} 2}=\sqrt{1-0,448}=0$, 552. Untuk mengetahui masing-masing koefisien jalur pada kedua model regresi tersebut dapat dilihat pada Gambar 1 .

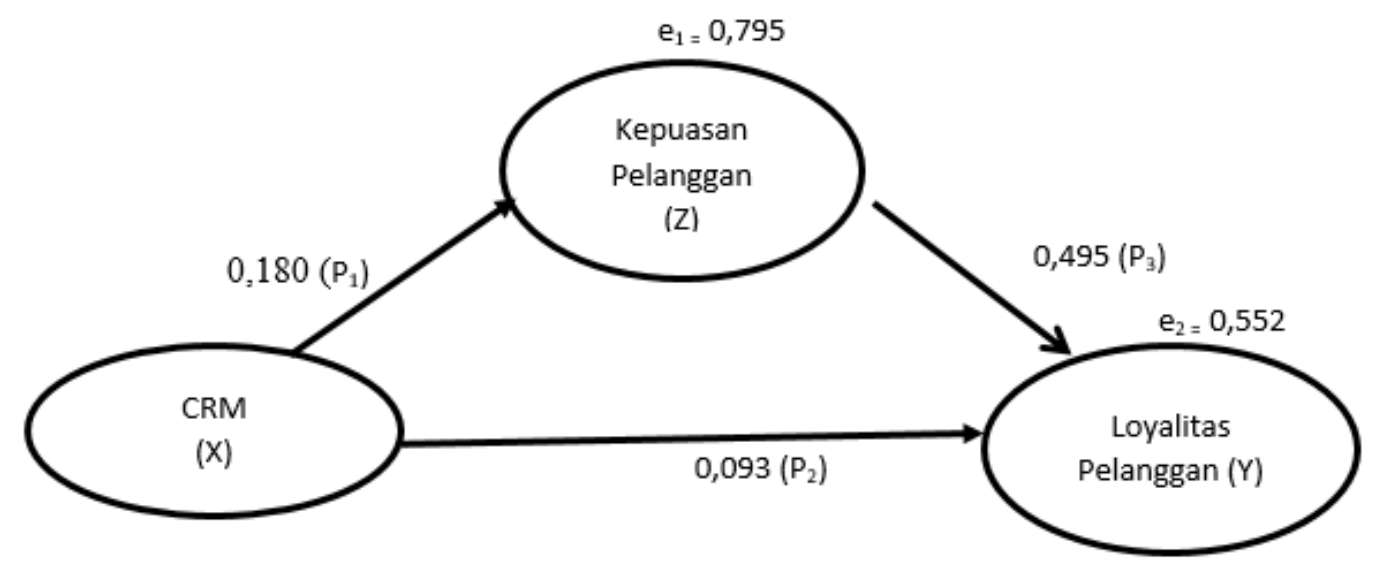

Gambar 1. Hasil Analisis Jalur (Path Analysis)

\section{Pengujian Variabel Intervening}

Hasil pengujian variable intervening pada penelitian ini dapat dilihat pada Tabel 5.

Tabel 5

Hasil Analisis Direct Effect dan Indirect Effect

\begin{tabular}{|c|c|c|c|}
\hline $\begin{array}{c}\text { Variabel } \\
\text { Penelitian }\end{array}$ & $\begin{array}{c}\text { Direct Effect } \\
\left(\mathrm{P}_{1}\right)\end{array}$ & $\begin{array}{c}\text { Indirect Effect } \\
\left(\mathrm{P}_{2} \times \mathrm{P}_{3}\right)\end{array}$ & Keterangan \\
\hline $\begin{array}{c}\text { Customer } \\
\text { Relationship } \\
\text { Management }\end{array}$ & 0,180 & 0,046 & $\begin{array}{c}\text { Direct Effect } \\
> \\
\text { Indirect } \\
\text { Effect }\end{array}$ \\
\hline
\end{tabular}


Berdasarkan Tabel 5, hasil pengujian diketahui bahwa indirect effect $<$ direct effect maka Kepuasan Pelanggan tidak menjadi variabel Intervening di antara Customer Relationship Management dan Loyalitas Pelanggan. Hal tersebut menunjukkan bahwa hipotesis IV tidak diterima yang menyatakan bahwa Customer Relationship Management tidak berpengaruh positif dan signifikan terhadap Loyalitas Pelanggan melalui Kepuasan Pelanggan.

\section{Pembahasan}

Berdasarkan hasil penelitian yang telah dikemukan diatas, maka dapat dirumuskan pembahasan pada penelitian ini, sebagai berikut:

1. Pengaruh Langsung CRM (X) terhadap Kepuasan Pelanggan (Z)

Berdasarkan hasil penelitian, dapat disimpulkan bahwa Customer Relationship Management berpengaruh positif dan signifikan terhadap Kepuasan Pelanggan di PT Pelabuhan Indonesia IV (Persero) Cabang Makassar. Hal ini diketahui dari jawaban responden dengan pernyataan mengenai Kepuasan Pelanggan yang mendapatkan rata-rata score 4,16 dikategorikan baik yaitu "Saya merasa puas dengan pelayanan PT Pelabuhan Indonesia IV (Persero) Cabang Makassar". Hal ini menunjukkan bahwa sebagian besar pelanggan setuju bahwa mereka puas dengan pelayanan ketika berada di Pelabuhan Indonesia IV (Persero) Cabang Makassar.

Hasil penelitian ini didukung dengan penelitian terdahulu yang dilakukan oleh Hara Paradisa Santoso (2017) yang menyatakan bahwa Customer Relationship Management berpengaruh positif dan signifikan terhadap Kepuasan Pelanggan di PT. Garuda Indonesia. Kemudian didukung dengan penelitian terdahulu yang dilakukan oleh Dzikiryati Yuni Ersi dan Hatane Samuel (2014) yang menyatakan bahwa Customer Relationship Management berpengaruh positif dan signifikan terhadap Kepuasan Pelanggan pada produk UKM berbasis bahan baku terigu di Jawa Timur

\section{2. $\quad$ Pengaruh Langsung CRM (X) terhadap Loyalitas Pelanggan (Y)}

Berdasarkan hasil penelitian, diketahui bahwa Customer Relationship Management berpengaruh positif dan signifikan terhadap Loyalitas Pelanggan di PT Pelabuhan Indonesia IV (Persero) Cabang Makassar. Hal ini diketahui dari jawaban responden dengan pernyataan mengenai Loyalitas Pelanggan yang mendapatkan rata-rata score 4,02 dikategorikan baik yaitu "Saya tidak tertarik untuk menggunakan jasa lain selain di PT Pelindo IV Persero (Cab Makassar)". Hal ini menunjukkan sebagian besar pelanggan setuju bahwa mereka tidak memilih jasa yang lain dikarenakan sudah merasakan dampak yang baik dari Customer Relationship Management saat menggunakan pelayanan jasa PT Pelabuhan Indonesia IV (Persero) Cabang Makassar.

Hasil penelitian ini didukung dengan penelitian oleh Junita Purbo Wisanti (2016) yang menyatakan bahwa Customer Relationship Management berpengaruh positif dan signifikan terhadap Loyalitas Pelanggan di kantor JNE Kota Salatiga. Kemudian didukung dengan penelitian yang dilakukan oleh Budiman dan Irnita Ajeng Yuli Muryati (2010) yang menyatakan bahwa Customer Relationship Management berpengaruh positif dan signifikan terhadap Loyalitas Pelanggan di Hotel Kristal.

\section{Pengaruh Langsung Kepuasan Pelanggan ( $\mathrm{Z}$ ) terhadap Loyalitas Pelanggan ( $\mathrm{Y}$ )}

Berdasarkan hasil penelitian, diketahui bahwa Kepuasan Pelanggan berpengaruh positif dan signifikan terhadap Loyalitas Pelanggan di PT Pelabuhan Indonesia IV (Persero) Cabang Makassar. Hal ini diketahui dari jawaban responden dengan pernyataan mengenai Loyalitas Pelanggan yang mendapatkan rata-rata score 4,37 dikategorikan Sangat baik yaitu "Saya akan merekomendasikan PT Pelabuhan Indonesia IV (Persero) Cabang Makassar kepada orang lain". 
Hal ini menunjukkan sebagian besar pelanggan setuju bahwa ketika pelanggan merasa puas, maka mereka akan merekomendasikan PT Pelabuhan Indonesia IV (Persero) Cabang Makassar kepada kerabat-kerabat mereka.

Hasil penelitian ini didukung dengan penelitian oleh Selvy Normasari, et al (2013) yang menyatakan bahwa Kepuasan Pelanggan berpengaruh positif dan signifikan terhadap Loyalitas Pelanggan yang menginap di Hotel Pelangi Malang.

4. Pengaruh tidak Langsung CRM (X) terhadap Loyalitas Pelanggan (Y) melalui Kepuasan Pelanggan $(\mathrm{Z})$

Pada penelitian ini, Kepuasan Pelanggan menjadi variabel intervening yang dapat memediasi hubungan antara Customer Relationship Management dengan Loyalitas Pelanggan. Namun hal tersebut tidak terbukti dilihat dari direct effect Customer Relationship Management terhadap Loyalitas Pelanggan lebih besar daripada indirect effect Customer Relationship Management melalui Kepuasan Pelanggan. Pada penelitian ini terlihat bahwa Kepuasan Pelanggan tidak dapat mempengaruhi Customer Relationship Management terhadap Loyalitas Pelanggan di PT Pelabuhan Indonesia IV (Persero) Cabang Makassar dikarenakan PT Pelabuhan Indonesia IV merupakan BUMN monopolistic di Indonesia khususnya timur bagian Indonesia, sehingga mau tidak mau pelanggan akan tetap setia menggunakan produk dan layanan yang disediakan PT Pelabuhan Indonesia IV (Persero). Meskipun pelanggan merasa sangat/puas atau tidak puas dengan pelayanan yang diberikan PT Pelabuhan Indonesia IV (Persero), hal ini akan tetap menuntut pelanggan untuk tetap loyal terhadap PT Pelabuhan Indonesia IV (Persero).

Penelitian ini memiliki kelemahan yaitu pada pelanggan yang tentunya puas atau tidak puas tetap harus menghadapi dan menikmati fasilitas pelayanan yang telah disediakan oleh PT Pelabuhan IV (Persero) karena PT Pelabuhan IV (Persero) yang memonopoli kegiatan usaha jasa kepelabuhan di Indonesia. Atas dasar monopoli, diharapkan PT Pelabuhan IV (Persero) tetap mempertahankan pelayanan yang selama ini dilakukan sehingga loyalitas konsumen yang menikmati pelayanan juga semakin bertambah. Kepuasan pelanggan sangat penting untuk mendukung loyalitas tetapi kepuasan juga dapat mendukung opini masyarakat tentang pelayanan di PT Pelabuhan IV (Persero) dan dipenelitian selanjutnya bisa mencoba menguji variabel penelitian ini di perusahaan persaingan bebas dan persaingan sempurna.

\section{Simpulan \& Rekomendasi}

Berdasarkan hasil penelitian yang bertujuan untuk mengetahui pengaruh CRM terhadap loyalitas melalui kepuasan pelanggan pada PT Pelindo IV (Persero) Cabang Makassar, maka dapat disimpulkan sebagai berikut :

1. Customer Relationship Management berpengaruh terhadap Kepuasan Pelanggan di PT Pelabuhan Indonesia IV (Persero) Cabang Makassar.

2. Customer Relationship Management berpengaruh terhadap Loyalitas Pelanggan di PT Pelabuhan Indonesia IV (Persero) Cabang Makassar.

3. Kepuasan Pelanggan berpengaruh terhadap Loyalitas Pelanggan di PT Pelabuhan Indonesia IV (Persero) Cabang Makassar.

4. Kepuasan Pelanggan tidak menjadi variabel intervening yang memediasi Customer Relationship Management dan Loyalitas Pelanggan di PT Pelabuhan Indonesia IV (Persero) Cabang Makassar.

Adapun saranrekomendasi yang penulis dapat berikan, ialah:

1. Bagi Perusahaan, Customer Relationship Management di PT Pelabuhan Indonesia IV (Persero) Cabang Makassar dapat dikategorikan sangat baik, namun untuk meningkatkan tingkat penggunaan jasa, PT Pelabuhan Indonesia IV (Persero) Cabang Makassar 
diharapkan dapat meningkatkan pelayanannya tanpa memandang klas atau status sosial, dimana karyawan harus dilatih untuk lebih ramah lagi kepada setiap pelanggan. PT Pelabuhan Indonesia IV (Persero) Cabang Makassar diharapkan dapat meningkatkan fasilitas khususnya pada bagian pelayanan. Dari segi Teknologi pelanggan menyatakan bahwa dapat terhubung ke jaringan wifi namun koneksinya sangat lambat, maka diharapkan perusahaan dapat menyediakan wifi dengan kualitas dan kecepatan yang lebih baik lagi.

2. Bagi Peneliti Selanjutnya, diharapkan dapat menjadi referensi dan terus mengembangkan penelitian ini. Penelitian ini menggunakan Kepuasan Pelanggan sebagai variabel intervening untuk memediasi Customer Relationship Management sebagai variabel bebas dan Loyalitas Pelanggan sebagai variabel terikat. Bagi peneliti selanjutnya dapat mengganti variabel dalam penelitian ini dengan variabel lain agar dapat menemukan variabel lain yang dapat membangun Loyalitas Pelanggan.

\section{Ucapan Terima Kasih}

Teruntuk kedua orangtua yang terkasih, yang sangat banyak melimpahkan doa dan kasih sayang serta memberikan semangat kepada saya, terimakasih yang sebesar besarnya, semoga diberkahi kesehatan dan kebahagiaan selalu. Till the rest of my life, I will love you both. Terima Kasih juga kepada PT Pelabuhan Indonesia IV (Persero) Cabang Makassar yang telah menyediakan penelitian dan fasilitas penelitian sehingga terselesaikannya penelitian ini.

\section{Referensi}

Budiman Dan Irnita Ajeng Yuli Muryati, (2010). Costumer Relationship Management (CRM) Dan Nilai Pelanggan Terhadap Loyalitas Pelanggan Di Hotel Kristal, Journal The WINNERS, Vol.11 No.2, September 2010.

Barnes , James G., (2003), Secrets of Customer Relationship Management (Rahasia Manajemen Hubungan Pelanggan, alih bahasa : Andreas Winardi, Andi Offset, Yogyakarta.

Chan, Syafruddin, (2003). CRM: Inovasi Pemasaran Yang Membuat Pelanggan Bertekuk Lutut, Gramedia Pustaka Utama, Jakarta.

Ersi, Dzikiryati Yuni dan Semuel, Hatane, (2014). Analysis CRM, kepuasan pelanggan dan loyalitas produk UKM berbasis bahan baku terigu di Jawa Timur. Jurnal Manajemen Pemasaran, 8(1): 1 8. Diakses pada tanggal 9 April 2015 dari http://jurnalpemasaran.petra.ac.id/index.php/mar/article/view/19093/18714

Hara, Paradisa Santoso, (2017). Pengaruh Customer Relationship Management dan Kualitas Pelayanan Terhadap Loyalitas Pelanggan Melalui Kepuasan Pelanggan Sebagai Variabel Intervening. Diakses dari: https://media.neliti.com/media/publications/203574pengaruh-customer-relationship-managemen.pdf

Martono, Nanang, (2011). Metode Penelitian Kuantitatif. Jakarta: PT Raya Grafindo Persada Kotler (2014), Manajemen Pemasaran

Latief, F. (2019). DIMENSI RELATIONSHIP MARKETING TERHADAP LOYALITAS PELANGGAN INDIHOME TRIPLE PLAY PT TELKOM. Bongaya Journal for Research in Management (BJRM), 2(1), 11-16. 
MASHUR, R., GUNAWAN, B. I., FITRIANY, F., ASHOER, M., HIDAYAT, M., \& ADITYA, H. P. K. P. (2019). Moving from traditional to society 5.0: Case study by online transportation business. The Journal of Distribution Science, 17(9), 93-102.

Normasari, Selvi, et al, (2013). Pengaruh Kualitas Pelayanan Terhadap Kepuasan Pelanggan, Citra Perusahaan dan Loyalitas Pelanggan, Jurnal Administrasi Bisnis(JAB). Vol 6. No 2. December 2013.

Singarimbun, S dan Effendi, S., (2006), Metode Penelitian Survei, Cetakan Kelima, Pustaka LP3ES, Jakarta

Sellyana Junaidi dan Basu Swastha Dharmmesta,(2016), "Pengaruh Ketidakpuasan Konsumen, Karakteristik Kategori Produk, Dan Kebutuhan Mencari Variasi Terhadap Keputuan Perpindahan Merek", Jurnal Ekonomi dan Bisnis Indonesia, Vo. 17, No. I, 91-104.

Sugiyono, (2017). Metode Penelitian Bisnis, Edisi Ketiga, Penerbit Alfabeta, Bandung

Tjiptono, Fandy. (2014). Pemasaran Jasa - Prinsip, Penerapan, dan Penelitian, Andi Offset, Yogyakarta

Wisanti, Junita Purbo, (2016). Analisis Pengaruh Customer Relationship Management (CRM) pada Kantor JNE Kota Salatiga dalam Upaya Meningkatkan Loyalitas Pelanggan. Repositori Institusi, Universitas Kristen Satya Wacana. 